\title{
THE FLYNN EMERGENCY RESUSCITATOR
}

\section{S. FLYNN, R.T., AND R. A. BROWNE, M.B., F.F.A.R.C.S.(ENG.)}

The FlynN Resuscrtator (Figure 1) was designed for the immediate treatment of patients with respiratory or cardiac insufficiency. The resuscitator consists of two parts:

(1) A device for administering intermittent positive pressure respiration.

(2) A flowmeter for supplying oxygen to patients who are breathing spontaneously.

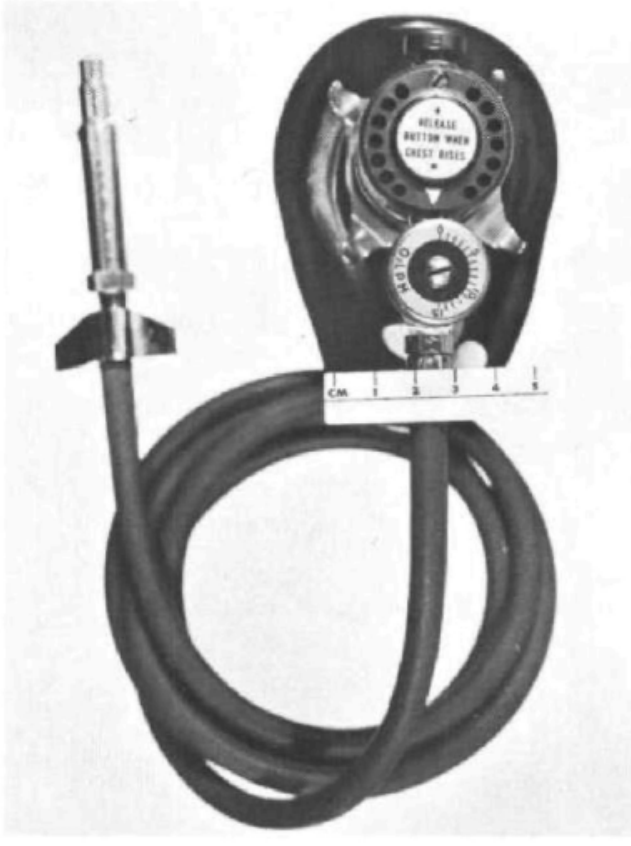

Figure 1. The Flynn resuscitator.

\section{Description of Resuscitator}

Oxygen at a pressure of $50 \mathrm{lb}$. per square inch is the driving force of the resuscitator, which can be operated either from a wall oxygen outlet or from a cylinder with appropriate reducing valve.

Oxygen enters the resuscitator at $A$ (Figure 2) and flows past the needle valve $B$. Gas then enters chamber $C$ which contains a metallic spring $D$. The function of $D$ is to keep a ball bearing $E$ against the shoulder of chamber $C$. A neoprene

'Departments of Inhalation Therapy and Anaesthesia, Hamilton Civic Hospitals. 


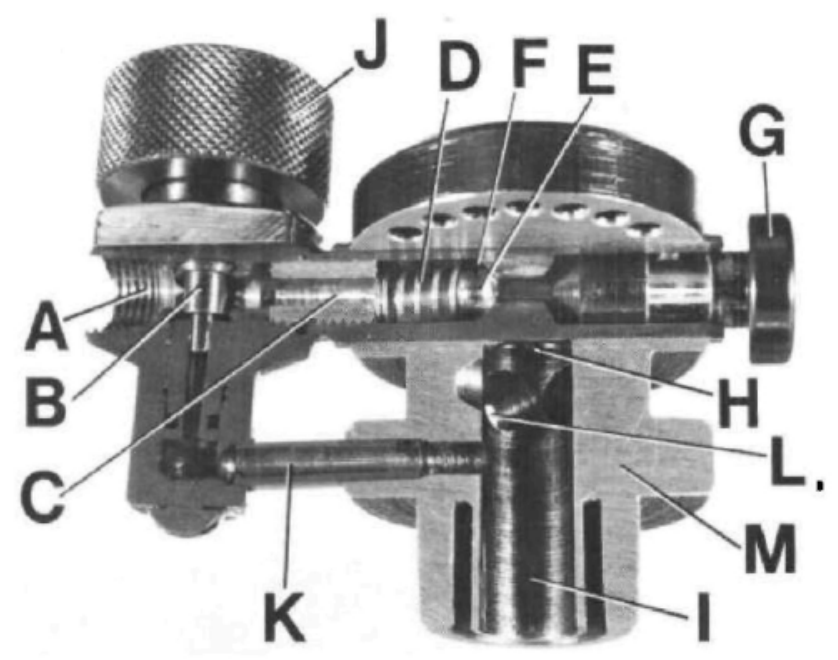

Figure 2. Longitudinal section of the Flynn resuscitator.

ring $F$ ensures a seal for the ball bearing against the shoulder. On depressing button $G$ the ball bearing is pushed away from the shoulder of chamber $C$ and oxygen flows past the displaced bearing and through a critical orifice $H$ into chamber $I$, the lower end of chamber $I$ is connected to the patient either by a facemask or an endotracheal tube. In the upper part of chamber $I$ are four ports, each $y^{\prime \prime}$ ' in diameter, which are open to the atmosphere.

As gas flows from the critical orifice $H$ into the larger chamber $I$, a venturi effect is created. Air is drawn in through the ports into chamber I when there is no resistance to the flow of oxygen from the lower part of the chamber. If there is resistance in excess of $54 \mathrm{~cm}$ of water, gas is blown off to the atmosphere through the ports, thus acting as a pressure relief valve. Thus in patients with low pulmonary compliance, approximately 100 per cent oxygen will be delivered. In patients with good pulmonary compliance, the concentration of oxygen delivered will rise to 100 per cent at the end of inspiration.

On releasing the button $G$ expiration starts and expired gases pass through the four ports to the atmosphere.

The resuscitator is capable of producing flow rates of 130 liters per minute.

For patients breathing spontaneously, an oxygen enriched atmosphere can be administered by opening the flowmeter $J$. Oxygen then flows through the connecting channel $K$ to the chamber $I$ of the resuscitator. Measured flow rates up to 15 liters per minute can be achieved. Inspired oxygen concentrations using the flowmeter are shown in Table I.

Six healthy adult patients who were anaesthetised and paralysed with succinylcholine were ventilated by the Flynn resuscitator using a facemask for a period of five minutes. These patients were ventilated by releasing button $G$ as soon as the chest was seen to rise, and at a rate of 16 breaths per minute. Table II illustrates that satisfactory ventilation was achieved as shown by oxygen and carbon dioxide tensions in arterial blood samples. 
TABLE I

INSPIRED OXYGEN CONCENTRATIONS ACHIEVED WITH DIFFERENT Flow Rates with Spontaneous Respiration

\begin{tabular}{cc}
\hline Flow rate (litres/min.) & inspired oxygen concentration (\%) \\
\hline 5 & 35 \\
7 & 40 \\
9 & 60 \\
12 & 70 \\
15 & 80 \\
\hline
\end{tabular}

TABLE IT

Arterial OXygen and Carbon Dioxide Tensions afTer Five MINUTES VENTILATION WITH THE Resuscitaton

\begin{tabular}{|c|c|c|}
\hline Patient & $\mathrm{P}_{2} \mathrm{O}_{2}$ & $\mathrm{PACO}$ \\
\hline $\begin{array}{l}1 \\
2 \\
3 \\
4 \\
5 \\
6\end{array}$ & $\begin{array}{l}280.8 \\
202.8 \\
380 \\
310 \\
294 \\
285\end{array}$ & $\begin{array}{l}25 \\
32 \\
27.1 \\
34.2 \\
35 \\
35.7\end{array}$ \\
\hline
\end{tabular}

Advantages of the Flynn Resuscitator

1. The final chamber has no moving parts which can malfunction due to vomit or secretions.

2. The body is sturdy (spun aluminum), It is $7.5 \mathrm{~cm}$ in length and weighs $6 \%$ oz.

3. It can be sterilized by any of the conventional methods, e.g. heat, gas.

4. It is simple to use.

5. It delivers 100 per cent oxygen.

6. It has a pressure relief mechanism at $54 \mathrm{~cm}$ water.

7. It is capable of high flow rate, thus permitting adequate ventilation in spite of mask leaks.

Its only disadvantage is that a source of compressed oxygen is necessary as its driving force. 